Pacific Journal of Mathematics

NEW CONDITIONS FOR SUBNORMALITY 


\title{
NEW CONDITIONS FOR SUBNORMALITY
}

\author{
Tavan T. TRent
}

\begin{abstract}
The purpose of this paper is to establish some new characterizations of subnormality. One of these characterizations is interesting, in that the conditions are applied to "one vector at a time". This type of criterion is applied to show that verifying subnormality can be reduced to considering the restrictions of the operator to its cyclic invariant subspaces.
\end{abstract}

Denote the bounded linear operators on a separable Hilbert space $H$ by $B(H)$. An operator $A \in B(H)$ is called subnormal if there exists an operator $N \in B(H \oplus H)$ so that $N$ is a normal operator, $H \oplus 0$ is invariant for $N$ and the restriction of $N$ to $H \oplus 0$ equals $A$ [8]. Some previous intrinsic characterizations of subnormality can be found in [2], [7], [8]. Also a summary of these results appears in [5].

An operator $T \in B(H)$ is called hyponormal if $T^{*} T-T T^{*} \geqq 0$. It is easy to see that $T$ is hyponormal if and only if $\|T x\| \geqq\left\|T^{*} x\right\|$ for all $x$ in $H$. By a theorem of Douglas [6], this is equivalent to the existence of an operator $K \in B(H)$ satisfying $\|K\| \leqq 1$ and $T^{*}=K T$. This fact was explicitly brought to the author's attention in [3].

Now the subnormal operators comprise a subset of the hyponormal ones. Thus the question arises as to whether the contraction operator $K$ relating $T^{*}$ and $T$, as above, has properties which enable one to tell whether $T$ is not only hyponormal, but subnormal as well. The following example shows that this is not the case. Let $K, T$, and $S$ denote Toeplitz operators with symbols $\bar{z}^{2}, \bar{z}+z^{3}$, and $z$, respectively. (Here $z$ stands for the identity function on the boundary of the unit disc.) Then $T^{*}=K T$ and $S^{*}=K S$, but $S$ is subnormal and $T$ is not [cf. 1]. The example for $T$ comes from [4].

However if $S$ is subnormal then so is $S^{n}$ for $n=0,1,2, \cdots$. Hence for $n=0,1,2, \cdots$ there exist contractions $K_{n} \in B(H)$ with $S^{* n}=K_{n} S^{n}$. Also it is known that there are hyponormal operators $T$, which are not subnormal, with $T^{n}$ hyponormal for $n=0,1, \cdots$ [13]. One might ask for conditions on the $K_{n}$ guaranteeing that if $T^{* n}=K_{n} T^{n}, n=0,1, \cdots$, then $T$ is subnormal. The following theorem provides these conditions.

THEOREM 1. Let $T \in B(H)$. The following conditions on $T$ are equivalent.

(a) $T$ is subnormal. 
(b) There exists a unitary operator $U \in B(H \oplus H)$ such that for $n=0,1, \cdots T^{* n}=P_{H} U^{n} T^{n}$, where $P_{H}$ is the orthogonal projection of $H \oplus H$ onto $H \oplus 0$.

(c) For $n=0,1, \cdots$

$$
T^{* n}=\left[\int_{\partial D} e^{\mathrm{int}} d Q(t)\right] T^{n}
$$

where $Q$ is a positive operator measure (denoted by POM) defined on the boundary of the unit disc, $\partial D$.

(d) There exists a sequence of operators $K_{n} \in B(H)$ satisfying $T^{* n}=K_{n} T^{n}$ for $n=0,1, \cdots$. Moreover if we define

$$
L_{n}= \begin{cases}K_{n} & n \geqq 0 \\ K_{n}^{*} & n<0\end{cases}
$$

then for any finite set $\left\{x_{0}, x_{1}, \cdots, x_{n}\right\}$ contained in $H$,

$$
\sum_{j, k \geq 0}^{n}\left\langle L_{j-k} x_{j}, x_{k}\right\rangle \geqq 0 \text {. }
$$

(e) There exists a sequence of operators $K_{n} \in B(H)$ satisfying $T^{* n}=K_{n} T^{n}$ for $n=0,1, \cdots$. Moreover if we define

$$
L_{n}= \begin{cases}K_{n} & n \geqq 0 \\ K_{n}^{*} & n<0\end{cases}
$$

then for each $x \in H$ and each $n=0,1, \cdots$ the matrix $\left[\left\langle L_{j-k} x, x\right\rangle\right]_{j, k \geqq 0}^{n}$ is positive definite.

Proof. $\quad(\mathrm{a}) \Rightarrow(\mathrm{b})$. Let $N$ be a normal extension of $T$ acting on $H \oplus H$. Since the kernel of $N$ reduces $N$ we may write $N=N_{1} \oplus 0$ acting on $(\operatorname{ker} N)^{\perp} \oplus \operatorname{ker} N$, where $N_{1}$ is normal and one-to-one. By normality, $N_{1}$ is also densely ranged, so if $N_{1}=U_{1}\left|N_{1}\right|$ is a polar decomposition of $N_{1}$, then $U_{1}$ is unitary. Let $V_{1}$ be any unitary operator in $B(\operatorname{ker} N)$ and define $U=U_{1} \oplus V_{1}$. Thus $N=U|N|$ where $U \in B(H \oplus H)$ is unitary. By normality $U_{1}$ commutes with $N_{1}$, thus $U$ commutes with $N$. Computing

$$
N^{* n}=(U|N|)^{* n}=U^{* n}|N|^{n}=U^{* 2 n}(U|N|)^{n}=\left[U^{* 2}\right]^{n} N^{n} .
$$

Projecting onto $H \oplus 0$ we see that (b) holds.

$(\mathrm{b}) \Rightarrow(\mathrm{c}) . \quad$ By the spectral theorem $U^{n}=\int_{\partial D} e^{\mathrm{int}} d E(t), n$ an integer, for a projection valued measure $E$ defined on $\partial D$. Hence for $n=1,2, \cdots$

$$
\begin{aligned}
T^{* n} & =P_{H} U^{n} P_{H} T^{n} \\
& =\left[\int_{\partial D} e^{\mathrm{int}} d Q(t)\right] T^{n}
\end{aligned}
$$


where $Q(t)=P_{H} E(t) P_{H}$ is a POM on $\partial D$.

$(c) \Rightarrow(d)$. By hypothesis we may choose

$$
K_{n}=\int_{\partial D} e^{\mathrm{int}} d Q(t) \text { for } n=0,1, \cdots
$$

Then

$$
K_{n}^{*}=\int_{\partial D} e^{-\mathrm{int}} d Q^{*}(t)=\int_{\partial D} e^{-\mathrm{int}} d Q(t)
$$

Hence

$$
L_{n}=\int_{\partial D} e^{\mathrm{int}} d Q(t) \text { for all integers } n \text {. }
$$

Take any finite subset $\left\{x_{0}, \cdots, x_{\mu}\right\}$ of $H$. Let $\left\{\Delta_{p}\right\}_{p=1}^{n}$ be any partition of $\partial D$ and choose $e^{i t_{p}} \in \Delta_{p}$.

Then for any fixed $p$

$$
\sum_{j, k \geq 0}^{M} e^{i j t_{p}} e^{-i k t_{p}}\left\langle Q\left(\Delta_{p}\right) x_{j}, x_{k}\right\rangle=\left\langle Q\left(A_{p}\right) \sum_{j=0}^{M} e^{i j t_{p}} x_{j}, \sum_{k=0}^{M} e^{i k t_{p}} x_{k}\right\rangle \geqq 0 .
$$

Summing over $p$ and interchanging the orders of summation, we get

$$
\sum_{j, k \geqq 0}^{M} \sum_{p=1}^{n} e^{i(j-k) t_{p}}\left\langle Q\left(\Delta_{p}\right) x_{j}, x_{k}\right\rangle \geqq 0 .
$$

The innermost sum is a Riemann sum for $\int_{\partial D} e^{i(j-k) t} d\left\langle Q(t) x_{j}, x_{k}\right\rangle$. We may conclude that

$$
\sum_{j, k \geq 0}^{M}\left\langle L_{j-k} x_{j}, x_{k}\right\rangle=\sum_{j, k \geq 0}^{M} \int_{\partial D} e^{i(j-k) t} d\left\langle Q(t) x_{j}, x_{k}\right\rangle \geqq 0 .
$$

$(\mathrm{d}) \Rightarrow(\mathrm{e})$. For any $x$ in $H$ and any finite subset $\left\{t_{0}, \cdots, t_{M}\right\}$ of complex numbers, denote $t_{j} x$ by $x_{j}$ and apply (d).

$(\mathrm{e}) \Rightarrow(\mathrm{d})$. By a result of Herglotz (see [9], p. 125), the hypotheses say that $\left\{\left\langle L_{n} x, x\right\rangle\right\}_{n=-\infty}^{\infty}$ is a trigonometric moment sequence for a positive Borel measure $\mu_{x}$ on $\partial D$, whose total variation is $\left\langle L_{0} x, x\right\rangle=$ $\|x\|^{2}$. Thus

$$
\left\langle L_{n} x, x\right\rangle=\int_{\partial D} e^{\mathrm{int}} d \mu_{x}(t) \text { for } n=0,1, \cdots .
$$

Fix $x$ in $H$. For each Borel set $\Delta \subset \partial D$ define the positive form $Q(\Delta)$ by

$$
\langle Q(\Delta) x, x\rangle=\int_{\Delta} 1 d \mu_{x}(t)
$$

Extend this form to a bilinear form on $H$ by polarization. The bilinear form is bounded since the positive form is. So the positive operator $Q(\Delta)$ is defined and $Q(\Delta)$ is in $B(H)$. 
By polarization and (1) we have

$$
\left\langle L_{n} x, y\right\rangle=\int_{\partial D} e^{\mathrm{int}} d\langle Q(t) x, y\rangle
$$

for $x, y$ in $H$. Thus

$$
\left\langle T^{* n} x, y\right\rangle=\left\langle L_{n} T^{n} x, y\right\rangle=\int_{\partial D} e^{\mathrm{int}} d\left\langle Q(t) T^{n} x, y\right\rangle .
$$

Thus (c) holds and so (d) must.

(d) $\Rightarrow(a)$. Let $\left\{x_{0}, \cdots, x_{n}\right\}$ be any finite subset of $H$. By (d)

$$
\sum_{j, k \geq 0}^{n}\left\langle L_{j-k} T^{j} x_{j}, T^{k} x_{k}\right\rangle \geqq 0 .
$$

Now if $k-j \geqq 0$,

$$
\begin{aligned}
\left\langle L_{j-k} T^{j} x_{j}, T^{k} x_{k}\right\rangle & =\left\langle T^{j} x_{j}, K_{k-j} T^{k-j} T^{j} x_{k}\right\rangle \\
& =\left\langle T^{j} x_{j}, T^{* k-j} T^{j} x_{k}\right\rangle \\
& =\left\langle T^{k} x_{j}, T^{j} x_{k}\right\rangle .
\end{aligned}
$$

A similar result follows when $k-j<0$, thus

$$
0 \leqq \sum_{j, k \geqq 0}^{n}\left\langle L_{j-k} T^{j} x_{j}, T^{k} x_{k}\right\rangle=\sum_{j, k \geqq 0}^{n}\left\langle T^{k} x_{j}, T^{j} x_{k}\right\rangle .
$$

It follows from the Bram-Halmos criterion that $T$ is subnormal [2].

For invertible operators, (d) is essentially Embry's condition [7]. In both cases "polar coordinates" are used. For Embry's the measures are supported on $[0,1]$ (radial) and in our case the relevant support set is $\partial D$ (angular).

Condition (e) of Theorem 1 gives a criterion for subnormality which involves looking at only one vector of $H$ at a time. A similar related result is due to Lambert [11]. As a consequence of this type of criterion, we have the following corollaries.

Fix $S \in B(H)$. Denote the closed linear span of $\left\{S^{k} x: k=0,1, \cdots\right\}$ by $H_{x}$.

CoROLlary 1. S is subnormal if and only if for every $x$ in a dense linear manifold of $H$ the restriction of $S$ to $H_{x}$ is subnormal.

Proof. The necessity of the condition is trivial. Let $\mathscr{D}$ denote the dense linear manifold of $H$ given in the hypotheses and let $\left.S\right|_{H_{x}}$ denote the restriction of $S$ to $H_{x}$. If $\left.S\right|_{H_{x}}$ is subnormal for all $x$ in $\mathscr{D}$, then so is $\left.(\lambda-S)\right|_{H_{x}}$. For all large $\lambda H_{x}$ is invariant for $(\lambda-S)^{-1}$. 
Thus without loss of generality we assume that $S$ is invertible and that

$$
\left(\left.S\right|_{H_{x}}\right)^{-1}=\left.S^{-1}\right|_{H_{x}} .
$$

Fix $x$ in $\mathscr{D}$. Since $\left.S\right|_{H_{x}}$ is subnormal there exist contractions $B_{n}$ in $B\left(H_{x}\right)$ such that

So

$$
\left.P_{H_{x}} S^{* n}\right|_{H_{x}}=\left.B_{n} S^{n}\right|_{H_{x}} \text { for } n=0,1, \cdots .
$$

$$
\left.P_{H_{x}} S^{* n} S^{-n}\right|_{H_{x}}=B_{n} \text {. }
$$

By (e) of Theorem 1 applied to $x$ and $B_{n}$ we see that

$$
\left[\left\langle S^{* j-k} S^{k-j} x, x\right\rangle\right]_{j, k \geqq 0}^{n} \text { is positive definite }
$$

for $n=0,1, \cdots$. But $S^{* n}=\left(S^{* n} S^{-n}\right) S^{n}$, so (e) of Theorem 1 now shows that $S$ is subnormal.

CoROLlaRy 2. $N$ is normal if for each $x$ in a dense linear manifold of $H$. We have $\left.N\right|_{H_{x}}$ is normal.

Proof. Let $\mathscr{D}$ denote the dense mainifold. For $x$ in $\mathscr{D},\left.N\right|_{H_{x}}$ normal implies that

$$
\|N x\|=\left\|P_{H} N^{*} x\right\| \leqq\left\|N^{*} x\right\| .
$$

But Corollary 2 says that $N$ is subnormal, thus hyponormal. Hence for $x$ in $\mathscr{D}$.

$$
\|N x\|=\left\|N^{*} x\right\| \text {. }
$$

Since $N$ and $N^{*}$ are continuous, the proof is complete.

An observation due to R. L. Moore might be of interest. Let $U$ be the unilateral shift of infinite multiplicity. In contrast to the result of Corollary 2, by model theory every cyclic normal operator of norm less than one can be obtained as the restriction of $U^{*}$ to a (cyclic) invariant subspace.

Using Corollary 1 and the fact that cyclic subnormal operators correspond to compactly supported Borel measures [2], it might be possible to find "functional" criteria for classes of subnormal operators. As a modest example motivated by a function used in [10], we have the following result.

THEOREM 2. Let $S \in B(H)$ and $\|S\| \leqq 1 . \quad S$ is an isometry if and only if for each $x$ in $H$ the function

$$
\dot{\phi}_{x}(z)=\left(1-|z|^{2}\right)\left\|(1-\bar{z} S)^{-1} x\right\|^{2} \text { is harmonic in the unit disc. }
$$




\section{The proof follows by an easy computation.}

We wish to thank R. L. Moore for his example and Warren Wogen for his suggestion that Theorem 1 which was originally proved for invertible operators should hold in general.

\section{REFERENCES}

1. B. Abrahamse, Subnormal Toeplitz operators and functions of bounded type, Duke Math. J., 43 (1976), 597-604.

2. J. Bram, Subnormal operators, Duke Math. J., (1955), 75-94.

3. K. Clancey, Seminormal operators, lecture notes, University of Georgia, 1978.

4. K. Clancey and B. Morrel, On the essential spectra of some Toeplitz operators, Proc. Amer. Math. Soc., 17 (1966), 367-379.

5. J. Conway, Lecture notes on subnormal operators, University of Indiana, 1978.

6. R. Douglas, On majorization, factorization, and range inclusion of operators on Hilbert space, Proc. Amer. Math. Soc., 17 (1966), 413-415.

7. M. Embry, Generalization of the Halmos-Bram criterion for subnormality, Acta Scien. Math., (Szeged) 35 (1973), 61-64.

8. P. Halmos, Normal dilations and extensions of operators, Summa Bras. Math., (1950), 125-134.

9. - A Hilbert Space Problem Book, Van Nostrand, New York, 1967.

10. T. L. Kriete and T. Trent, Growth near the boundary in $H^{2}(u)$ spaces, Proc. Amer. Math. Soc., 62 (1977), 83-88.

11. A. Lambert, Subnormality and weighted shifts, J. London Math. Soc., 14 (1976), 476-480.

12. W. Rudin, Functional Analysis, McGraw-Hill, New York, 1973.

13. J. Stampfli, Hyponormal operators and spectral density, Trans. Amer. Math. Soc., 117 (1965), 709-718.

Received January 2, 1980.

University of Alabama

UNIVERSITY, AL 35486 


\title{
PACIFIC JOURNAL OF MATHEMATICS
}

\section{EDITORS}

\author{
DoNALD BABBITT (Managing Editor) \\ University of California \\ Los Angeles, CA 90024 \\ Hugo RossI \\ University of Utah \\ Salt Lake City, UT 84112 \\ C. C. MOORE and ANDrew OGG \\ University of California \\ Berkeley, CA 94720
}

J. DugundJI

Department of Mathematics

University of Southern California

Los Angeles, CA 90007

R. FINN and J. MILGRAM

Stanford University

Stanford, CA 94305

\section{ASSOCIATE EDITORS}
R. Arens
E. F. BeCKenbaCH
B. H. NeumanN
F. WOLF
K. YoSHIDA

\section{SUPPORTING INSTITUTIONS}

UNIVERSITY OF ARIZONA

UNIVERSITY OF BRITISH COLUMBIA

CALIFORNIA INSTITUTE OF TECHNOLOGY

UNIVERSITY OF CALIFORNIA

MONTANA STATE UNIVERSITY

UNIVERSITY OF NEVADA, RENO

NEW MEXICO STATE UNIVERSITY

OREGON STATE UNIVERSITY

\author{
UNIVERSITY OF OREGON \\ UNIVERSITY OF SOUTHERN CALIFORNIA \\ STANFORD UNIVERSITY \\ UNIVERSITY OF HAWAII \\ UNIVERSITY OF TOKYO \\ UNIVERSITY OF UTAH \\ WASHINGTON STATE UNIVERSITY \\ UNIVERSITY OF WASHINGTON
}

The Supporting Institutions listed above contribute to the cost of publication of this Journal, but they are not owners or publishers and have no responsibility for its content or policies.

Mathematical papers intended for publication in the Pacific Journal of Mathematics should be in typed form or offset-reproduced, (not dittoed), double spaced with large margins. Please do not use built up fractions in the text of the manuscript. However, you may use them in the displayed equations. Underline Greek letters in red, German in green, and script in blue. The first paragraph or two must be capable of being used separately as a synopsis of the entire paper. Please propose a heading for the odd numbered pages of less than 35 characters. Manuscripts, in triplicate, may be sent to any one of the editors. Please classify according to the scheme of Math. Reviews, Index to Vol. 39. Supply name and address of author to whom proofs should be sent. All other communications should be addressed to the managing editor, or Elaine Barth, University of California, Los Angeles, California, 90024.

50 reprints to each author are provided free for each article, only if page charges have been substantially paid. Additional copies may be obtained at cost in multiples of 50 .

The Pacific Journal of Mathematics is issued monthly as of January 1966. Regular subscription rate: $\$ 102.00$ a year $(6$ Vols., 12 issues). Special rate: $\$ 51.00$ a year to individual members of supporting institutions.

Subscriptions, orders for numbers issued in the last three calendar years, and changes of address shoud be sent to Pacific Journal of Mathematics, P.O. Box 969, Carmel Valley, CA 93924, U.S.A Old back numbers obtainable from Kraus Periodicals Co., Route 100, Millwood, NY 10546.

\section{PUBLISHED BY PACIFIC JOURNAL OF MATHEMATICS, A NON-PROFIT CORPORATION}

Printed at Kokusai Bunken Insatsusha (International Academic Printing Co., Ltd.). 8-8, 3-chome, Takadanobaba, Shinjuku-ku, Tokyo 160, Japan. 


\section{Pacific Journal of Mathematics}

Vol. 93, No. $2 \quad$ April, 1981

Ilya Eugene Blum and Srinivasa Swaminathan, Continuous selections and

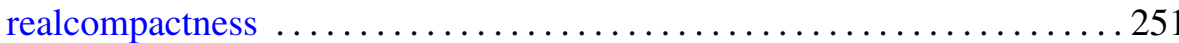

Lawrence James Brenton, Differentiably $k$-normal analytic spaces and extensions of holomorphic differential forms $\ldots \ldots \ldots \ldots \ldots \ldots \ldots 261$

Jo-Ann Deborah Cohen, Topologies on the ring of integers of a global field ................................................... 269

Robert Jay Daverman, Detecting the disjoint disks property $\ldots \ldots \ldots \ldots 277$

Edmund H. Feller, Rings where the annihilators of $\alpha$-critical modules are prime ideals ....................................... 299

Richard Elam Heisey and Henryk Torunczyk, On the topology of direct

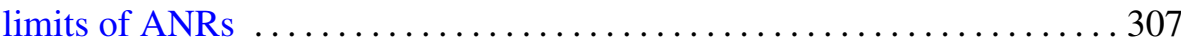

Gerald William Johnson and David Lee Skoug, Notes on the Feynman

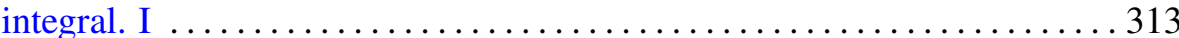

Michael S. Keane and Stuart Jay Sidney, Distinguishing a plane curve

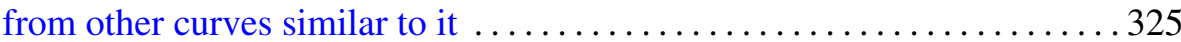

Leonid A. Luxemburg, On compact metric spaces with noncoinciding

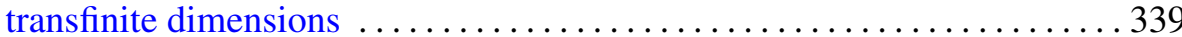

Chun Ming Ma, A uniqueness theorem for Navier-Stokes equations . . . . . . 387

Donald J. Newman and Theodore Joseph Rivlin, A characterization of the weights in a divided difference . . . . . . . . . . . . . . . . . . . 407

Marc Aristide Rieffel, $C^{*}$-algebras associated with irrational rotations $\ldots .415$

Kichi-Suke Saito, Invariant subspaces for finite maximal subdiagonal algebras

Frederic W. Shultz, Dual maps of Jordan homomorphisms and ${ }^{*}$-homomorphisms between $C^{*}$-algebras $\ldots \ldots \ldots \ldots$

Vsevolod Alekseevich Solonnikov, On the solvability of boundary and initial-boundary value problems for the Navier-Stokes system in domains with noncompact boundaries

Tavan Thomas Trent, New conditions for subnormality

L. E. Ward, Extending Whitney maps ..................

Leslie Wilson, Jets with regular zeros

Sergio Eduardo Zarantonello, The sheaf of $H^{p}$-functions in product 